\title{
Praticidade e sustentabilidade no processo metodológico de pré- desenvolvimento de produtos
}

\section{Sustainability and practice in the pre-product development methodological process}

\author{
Eloiza Kohlbeck \\ Graduanda em Engenharia de Produção pela Universidade do Estado de Santa Catarina (Udesc) - \\ eloiza.kohlbeck2706@gmail.com - http://orcid.org/0000-0003-4299-742X \\ Beatriz Christina Baimler \\ Graduanda em Engenharia de Produção pela Universidade do Estado de Santa Catarina (Udesc) - \\ baimlerbeatriz@gmail.com - https://orcid.org/0000-0001-9418-6800
}

Fernanda Hansch Beuren

Doutora em Engenharia de Produção pela Universidade Federal de Santa Catarina (UFSC). Professora na Universidade do Estado de Santa Catarina (Udesc) - fernanda.beuren@udesc.br - http://orcid.org/0000-0003-1338-9660

Alexandre Borges Fagundes

Doutor em Tecnologia pela Universidade Tecnológica Federal do Paraná (UTFPR). Professor na Universidade do Estado de Santa Catarina (Udesc) - alexandre.fagundes@udesc.br - http://orcid.org/0000-0003-2941-1842

\section{Delcio Pereira}

Doutor em Administração pela Universidade Positivo. Professor na Universidade do Estado de Santa Catarina (Udesc) delcio.pereira@udesc.br -http://orcid.org/0000-0002-7635-3086

\section{Resumo}

O crescente consumo de produtos, o aumento populacional e os novos hábitos da sociedade vêm colaborando para a intensificação da problemática ambiental. Dessa forma, surge a necessidade de conscientização ambiental coletiva e do desenvolvimento de novos produtos, que solucionem ou amenizem estes impactos. Para maior aperfeiçoamento e otimização destes produtos, há a necessidade de utilizar as etapas do prédesenvolvimento de produtos, as quais abrangem o planejamento estratégico e de projetos. Para tanto, elaborou-se uma proposta de desenvolvimento de um produto menos impactante ambientalmente, desde a etapa do brainstorming de ideias até a comercialização do produto. Tem-se como principais resultados, a redução de resíduos sólidos, pois minimiza o consumo de embalagens e de material para sua confecção; e um produto em forma de protótipo, o qual pode ser manuseado e testado sua usabilidade por possíveis usuários. Palavras-chave: Artesanato-Equipamento e acessórios. Projeto de produto. Produtos ecológicos. Sustentabilidade e meio ambiente.

\begin{abstract}
The growing consumption of products, the population increase and the new habits of society have been contributing to the intensification of environmental issues. Thus, there is a need for collective environmental awareness and the development of new products that address or mitigate these impacts. For further improvement and optimization of these products, there is a need to use the product pre-development steps, which include strategic and project planning. To this end, a proposal was developed for the development of a less environmentally impactful product, from the brainstorming of ideas to the commercialization of the product. The main results are the reduction of solid waste, as it minimizes the consumption of packaging and material for its manufacture; and a prototype product that can be handled and tested for usability by potential users.
\end{abstract}

Keywords: Handicraft-Equipment and supplies. Product design. Green products. Sustainability and the environment 


\section{INTRODUÇÃO}

Entre as principais prioridades do desenvolvimento humano estão o crescimento industrial, a inovação científica e tecnológica, a urbanização e a produção e o consumo em massa. Entretanto, este sistema econômico capitalizado está produzindo níveis excessivos de resíduos e de impactos ambientais, cobrando um preço alto às pessoas e ao planeta (CROCKER, 2017).

Uma grande complicação é o elevado consumo de embalagens. Segundo dados do Ministério do Meio Ambiente (MMA), atualmente um terço do lixo doméstico é constituído por embalagens, representando cerca de 25 mil toneladas destinadas todos os dias à depósitos de lixo (MMA, 2018). Dessa forma, inúmeros problemas ambientais são apontados, entre eles, a poluição do solo.

É necessário o desenvolvimento de políticas voltadas à prevenção da poluição do solo e a recuperação de áreas já deterioradas. Essa tarefa cabe, principalmente, a órgãos públicos e empresariais. Os órgãos públicos devem incentivar a conscientização e a adoção de medidas para prevenir e para punir aqueles que contribuem para a poluição. As empresas devem reduzir a geração de resíduos ou reutilizá-los em seu processo produtivo na forma de subprodutos, promovendo medidas para viabilizar a implantação da Logística Reversa, a qual Barradas, Martins e Moraes (2011) definem como o processo que consiste no retorno do produto do ponto de consumo até o ponto de origem.

Não apenas os órgãos públicos e empresas, mas também a população, deve se conscientizar evitando a degradação dos recursos naturais, a partir da conscientização de que eles são limitados e imprescindíveis para o equilíbrio do meio ambiente. Segundo Silveira (2014) é fundamental que a sociedade se torne mais consciente em relação ao consumo, evitando excessos e desperdícios, e mais consciente do lixo gerado cotidianamente. Desse modo, a gestão dos resíduos sólidos torna-se essencial para a amenizar os impactos ambientais.

O desenvolvimento de produtos e serviços sustentáveis tornou-se um suporte pragmático da indústria, envolvendo uma série de estratégias destinadas a maximizar o desempenho ambiental (MAXWELL; SHEATE; VORST, 2006). Nesse contexto, é de fundamental importância a relação entre sustentabilidade e praticidade, visto que a sociedade, justificada pela falta de tempo e pela dedicação ao trabalho, busca pelo desenvolvimento de produtos e serviços neste viés (CUNHA, 2017). 

Delcio Pereira

Este artigo tem como objetivo a proposta de desenvolvimento de um produto que amenize os impactos causados ao meio ambiente. Para tanto utilizou-se das etapas do pré-desenvolvimento de produtos, abrangendo planejamento estratégico e planejamento de projetos (ROZENFELD et al., 2006; TROTT, 2012).

\section{REFERENCIAL TEÓRICO}

Antes da Revolução Industrial, o resíduo produzido pela sociedade era basicamente sobras de alimentos. A partir de então, foram incorporados no cotidiano da população novos materiais, como plásticos, vidros, borrachas, isopor e alumínio, sendo estes reconhecidos pela sua difícil decomposição (DIAS, 2016). Com isso, aumentou acentuadamente a quantidade de resíduos gerados, agravando a problemática ambiental de contaminação do meio ambiente e consequentemente a geração de riscos à saúde humana (DIAS, 2016).

Diante do problema ambiental causado pelo crescente aumento na quantidade de resíduos sólidos gerados pela intensa produção de produtos nos últimos anos, diversas estratégias vêm sendo tomadas visando amenizar estes problemas, garantindo um desenvolvimento ecologicamente correto nos âmbitos social, ambiental e econômico (STOCK; SELIGER, 2016).

Esta conjuntura oferece inúmeras oportunidades para a realização de manufatura sustentável, voltados a solução ou amenização desta problemática ambiental. Faz-se então, o redirecionamento da logística do pensamento predominantemente econômico para um planejamento de longo prazo que abranja também aspectos ambientais e sociais (STOCK; SELIGER, 2016; SLOMSKI et al., 2012).

\subsection{Inovação e Sustentabilidade}

O solo contribui para inúmeras atividades essenciais ao ser humano, entre elas a agricultura e a pecuária. Entretanto, sua preservação nem sempre é difundida pela população, a qual provoca processos como erosão e voçoroca, impossibilitando seu uso (VIANNA, 2015). De acordo com Burghardt et al. (2016) o acúmulo de resíduos produz elementos tóxicos, os quais contaminam rios, córregos e lençóis freáticos.

Analisando o contexto de poluição dos recursos naturais, o gerenciamento de resíduos abrange a sociedade como um todo, envolvendo desde atividades individuais como a triagem e 
Eloiza Kohlbeck, Beatriz Christina Baimler, Fernanda Hansch Beuren, Alexandre Borges Fagundes, Delcio Pereira

destinação correta desses resíduos, até atitudes conjuntas incentivadas pela Política Nacional de Resíduos Sólidos. Um exemplo é a implementação de acordos setoriais entre o poder público e fabricantes, importadores, distribuidores ou comerciantes para a implantação da logística reversa (FAGUNDES, 2015).

A Associação Brasileira de Embalagens (ABRE) realizou uma análise do valor bruto de embalagens produzidas em 2018, e constatou que houve uma movimentação de $R \$ 78,5$ bilhões, 0 que representou um crescimento de 10,4\% em relação à 2017. Estimou-se que plásticos, embalagens celulósicas e metálicas representaram aproximadamente $90 \%$ do montante total (ABRE, 2019). O Gráfico 1 representa este aumento na produção entre os anos de 2014 e 2018.

Gráfico 1 - Evolução na produção de embalagens.

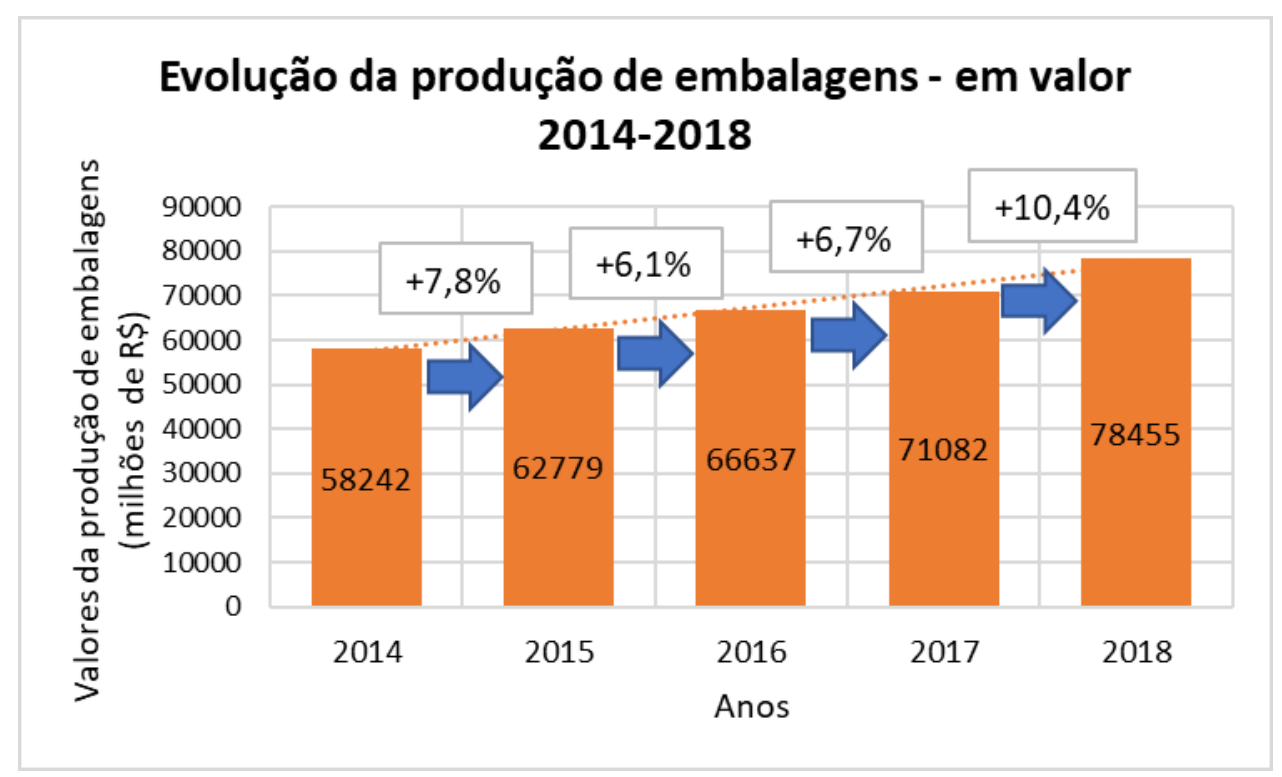

Fonte: Adaptado de ABRE (2019).

Contudo, atualmente o homem vem apresentando uma nova concepção sobre a poluição, analisando seus atos e criando tecnologias sustentáveis (BURGHARDT et al., 2016). Verificou-se também uma mudança no comportamento do mercado, o qual está mais ávido por produtos inovadores, flexíveis e adaptáveis (FERREIRA; MICHELS, 2013).

É cada vez mais evidente a atenção das organizações em relação ao esgotamento de recursos naturais, ao desenvolvimento de produtos e serviços "verdes" e de práticas sustentáveis (BULLARD; MANCHANDA, 2013). 

Delcio Pereira

Com a minimização de recursos de produção, há a redução dos impactos ambientais provenientes daquilo que não é mais utilizado. Isto ocorre não somente pela diminuição na produção de materiais, como também porque assim evita-se sua transformação, seu transporte e a necessidade de descarte (MANZINI; VEZZOLI, 2016).

\subsection{Inovações X Praticidade}

O número de pessoas que moram sozinhas no Brasil vem aumentando. Nessa proporção, o mercado deve ser capaz de suprir as demandas deste público, visto que seu consumo vem crescendo em média $6 \%$ ao ano. Esta parcela da população é responsável por $40 \%$ do aumento de vendas de produtos práticos e em porções individuais (VENTURA, 2010).

Pessoas que moram sozinhas possuem suas próprias demandas e formas pessoais de consumo de produtos e serviços. Elas buscam a otimização de seu tempo a fim de conciliar atividades pessoais e profissionais com a necessidade da administração de sua casa. Assim, produtos que facilitam as tarefas domésticas, que ajudam a administrar o tempo, ao otimizar compromissos e tarefas extras, possuem grande aceitabilidade (VENTURA, 2010).

É imprescindível que uma organização tenha como objetivo a inovação e a elevação da capacitação de níveis de conhecimento para tornar viável a prática do empreendimento. Dessa forma, faz-se necessário levar em consideração aplicações de ergonomia, as quais garantirão uma usabilidade mais facilitada para o consumidor (MAFRA; VIDAL, 2008).

\subsection{Desenvolvimento de novos produtos X Artes plásticas}

O processo de desenvolvimento de produtos é constituído por um conjunto de atividades, que visa satisfazer a demanda da população, integrar-se a outros produtos, incorporar novas tecnologias e adequar-se a restrições legais, sendo fundamental realizar as especificações do projeto, para que a manufatura esteja hábil à produzi-lo e acompanha-lo após seu lançamento (ROZENFELD et al., 2006).

Segundo Costa e Toledo (2016) e Souza (2016) o processo de desenvolvimento de novos produtos (PDP), o qual é composto por três macrofases de desenvolvimento: pré-desenvolvimento, desenvolvimento e pós-desenvolvimento (Figura 1) visam atender a proposta desde o planejamento estratégico até a destinação final do produto a ser criado. Neste trabalho utilizou-se especificamente 
a etapa de pré-desenvolvimento, planejamento do projeto de um produto. Para as empresas é essencial este planejamento prévio para a elaboração de um novo produto e está relacionado ao processo de inovação empresarial (ROZENFELD et al., 2006).

Figura 1 - Etapas do desenvolvimento de produtos.

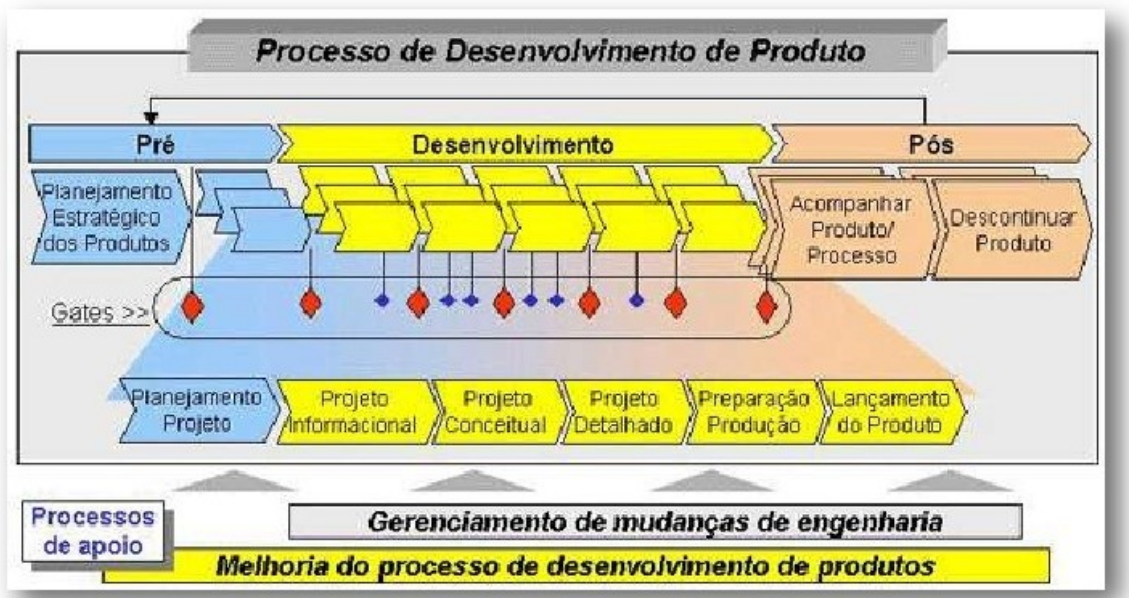

Fonte: (ROZENFELD et al., 2006).

As etapas do pré-desenvolvimento recebem nomes diferentes na literatura, mas são citadas basicamente as atividades de identificação de oportunidades; seleção de oportunidades; geração de ideias; seleção de ideias; desenvolvimento de conceito; seleção de conceitos e planejamento de projetos. Todos estes processos são essenciais e devem estar presentes no desenvolvimento de novos produtos, independente do ramo de atuação da empresa (COSTA; TOLEDO, 2016).

Costa e Toledo (2016) citam que o pré-desenvolvimento está diretamente relacionada a questões como criatividade, descobertas e viabilidade (financeira, comercial e técnica). Deste modo, sua abordagem é constante em empresas e pesquisas, pois uma boa gestão das atividades do prédesenvolvimento pode influenciar no sucesso de novos produtos e na redução de custos no processo do desenvolvimento. O Quadro 1 lista as vantagens da implantação do Pré-Desenvolvimento.

Quadro 1 - Importância do Pré-Desenvolvimento.

\begin{tabular}{|c|}
\hline Focaliza nos projetos prioritários definidos pela empresa \\
\hline Dá início à produção de modo mais rápido e eficiente \\
\hline Disponibiliza critérios claros para avaliação dos projetos em andamento \\
\hline Promove o uso eficiente dos recursos de desenvolvimento \\
\hline
\end{tabular}

Fonte: Adaptado de Rozenfeld et al. (2006, p. 59-60). 

Delcio Pereira

O sucesso no desenvolvimento de produtos depende do gerenciamento das incertezas, de modo a minimizá-las por meio de informações precisas e, que no momento em que as decisões são tomadas, haja um controle dos requisitos a serem satisfeitos e uma atenção a eventuais mudanças ou atualizações no mercado (ROZENFELD et al., 2006).

Em países como o Brasil, que se apresentam em fase de ascensão econômica e tecnológica, o processo de desenvolvimento de produtos se concentra na adaptação e aperfeiçoamento de artigos já lançados por países desenvolvidos, onde aglomeram-se multinacionais e um mercado com maior poder aquisitivo (ROZENFELD et al., 2006).

Para que o processo de inovação por meios sustentáveis difunda-se na sociedade, é fundamental o investimento, público ou privado, nacional ou internacional, em empresas com capacidade de desenvolver produtos ou serviços inovadores e competitivos, usando de conhecimentos internos. Que estas empresas também busquem e valorizem conhecimento acadêmico e científico, de modo a retornarem à sociedade por meio de novas tecnologias desenvolvidas. Além disso, a educação da população assegura a imortalização e aprimoramento desse processo (CALMANOVICI, 2011).

O comportamento do consumidor está relacionado com os aspectos ecológicos e, ao mesmo tempo, procura elementos que interliguem sentimentos de identidade com o desenvolvimento sustentável. Nesse contexto, houve uma ascendência de práticas produtivas artesanais (FREITAS; ROMERO, 2004).

A interligação da arte com o trabalho e o modo simples de viver almejado por muitas pessoas, vem contribuindo para uma crescente necessidade material e imaterial de consumo e uma oportunidade para a geração de renda com o desenvolvimento de novos produtos (FREITAS; ROMERO, 2004).

\section{MÉTODOS DE PESQUISA}

Para satisfazer a proposta metodológica de desenvolvimento de um novo produto, utilizouse como base as etapas de pré-desenvolvimento de produtos e serviços, descritas por Rozenfeld et al. (2006), conforme ilustrado na Figura 2. 
Figura 2 - Etapas do Pré-Desenvolvimento.

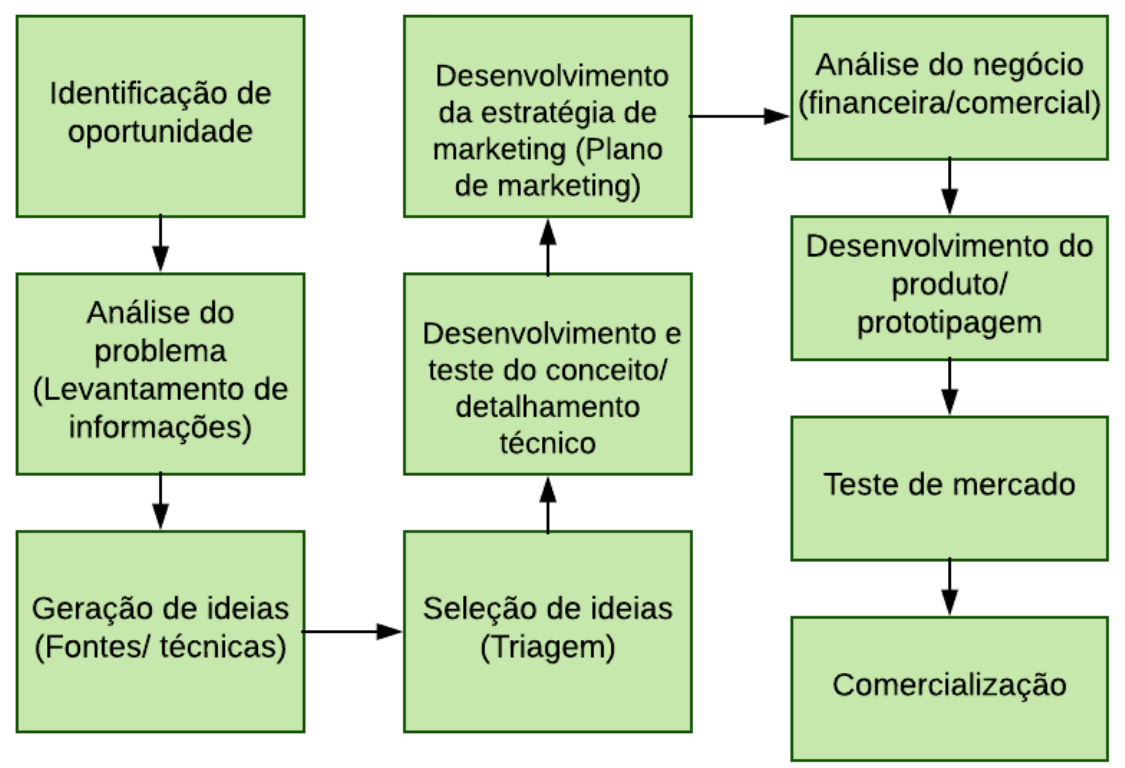

Fonte: Adaptado de Rozenfeld et al. (2006).

Iniciou-se o trabalho identificando os principais problemas que os produtos apresentam e/ou ocasionam no meio ambiente. Dentre os citados, definiu-se o problema poluição do solo. Em seguida, buscou-se informações sobre o problema para então realizar a geração de ideias. Foi desenvolvido um novo produto com o objetivo de solucionar ou amenizar seus impactos. E assim, surgiu a identificação de uma oportunidade.

Foi analisado o tema poluição do solo, pesquisando informações para aquisição de conhecimento e realizada uma pesquisa bibliográfica nas principais bases de dados em busca do estado da arte sobre o tema abordado. Das quais foram selecionadas Scopus, Science Direct e Google Acadêmico, a partir de busca pelo Portal de Periódicos da CAPES.

Assim, surgiram 30 ideias, as quais foram debatidas em um brainstorming que permitiu o compartilhamento de sugestões eficazes de solucionar ou amenizar o problema proposto. De acordo com Campos e Gaião (2015) o brainstorming é uma técnica utilizada para levantar várias ideias por meio de uma integração entre os indivíduos de um grupo.

A seguir, foi desenvolvido um método de triagem, onde foi utilizado o software Excel para a realização de tabelas comparativas. Para isso, foram estabelecidos cinco critérios para selecionar a melhor ideia entre as 30 estabelecidas, sendo elas: sustentabilidade, rentabilidade, praticidade, 
recursos disponíveis e durabilidade. Assim, foi possível escolher o produto melhor avaliado: "Pincel Troca Cerdas".

A etapa seguinte foi o desenvolvimento de um questionário para analisar a aceitabilidade que esse novo produto terá no mercado. Foi selecionado o público-alvo, pessoas que adquirem pincel de artesanato com frequência. Ao todo, 39 pessoas responderam às questões, das quais 11 são amadores do artesanato, 12 são profissionais da Educação Infantil ${ }^{1}$ e 16 são alunos de um curso profissionalizante.

Já que o número de entrevistados em cada parcela da população foi diferente, realizou-se cálculos para a obtenção de sua porcentagem, a qual possibilitou a comparação entre os resultados.

Tendo em mãos as respostas dos questionários, foram elaborados gráficos utilizando o software Excel, o qual possibilitou comparar e ilustrar os dados disponibilizados pelos entrevistados. Dessa maneira, foi possível desenvolver um estudo de mercado para o "Pincel Troca Cerdas", analisando seu tamanho, estrutura e comportamento.

Na sequência foi realizado o plano de marketing, no qual foi estipulada a estratégia de distribuição do "Pincel Troca Cerdas", as metas de vendas e de lucros à longo prazo e o orçamento de marketing para o primeiro ano.

Em seguida, foi estabelecido o valor de comercialização do produto. Para isso, foram listados todos os custos gerados com a compra de materiais e feita uma análise em diversas lojas para encontrar o melhor preço para aquisição e que, ao mesmo tempo, oferecesse um produto de qualidade.

Também foram analisados todos os custos envolvidos (custos fixos e variáveis) e os valores de confecção e comercialização. Assim, foi possível calcular o lucro, representado por meio de tabelas e realizar uma análise do negócio, na qual foram desenvolvidas estratégias para agregar valor às partes interessadas.

Na sequência, foi elaborado o desenho técnico do "Pincel Troca Cerdas", utilizando o software Autodesk Inventor, o qual permitiu a realização da prototipagem do produto, utilizando impressão 3D para a visualização detalhada do produto. Também foi realizada a prototipagem do produto em escala real, utilizando material alternativo.

\footnotetext{
${ }^{1}$ Foram selecionados professores, que utilizam pincéis cotidianamente em sua metodologia de ensino. 


\section{ANÁLISES DOS RESULTADOS}

Após a identificação da oportunidade de desenvolvimento de um novo produto baseado na problemática "poluição do solo", de sua análise por meio do levantamento bibliográfico e da geração de ideias a partir do brainstorming, obteve-se 30 ideais. Na sequência foi feita uma triagem a fim de selecionar a melhor das ideias apresentadas. Para isso, estabeleceram-se cinco critérios para avaliação em pares: sustentabilidade, rentabilidade, praticidade, recursos disponíveis e durabilidade.

O Quadro 2 apresenta uma parcela da triagem realizada com o critério sustentabilidade. Dessa forma, foi escolhido o produto mais listado nas tabelas, por representar aquele que mais se destacou: "Pincel Troca Cerdas".

Quadro 2 - Triagem com o critério sustentabilidade.

\begin{tabular}{|c|c|c|c|}
\hline Sustentabilidade & $\begin{array}{c}\text { Chave combinada } \\
\text { (ajustável dos dois } \\
\text { lados) }\end{array}$ & $\begin{array}{l}\text { Serrote afiado dos dois } \\
\text { lados com diferentes } \\
\text { formas }\end{array}$ & $\begin{array}{c}\text { Pincel Troca } \\
\text { Cerdas }\end{array}$ \\
\hline $\begin{array}{l}\text { Chave combinada } \\
\text { (ajustável dos dois } \\
\text { lados) }\end{array}$ & $x$ & $\begin{array}{l}\text { Chave combinada } \\
\text { (ajustável dos dois } \\
\text { lados) }\end{array}$ & $\begin{array}{c}\text { Pincel Troca } \\
\text { Cerdas }\end{array}$ \\
\hline $\begin{array}{c}\text { Serrote afiado dos dois } \\
\text { lados com diferentes } \\
\text { formas }\end{array}$ & $\begin{array}{c}\text { Chave combinada } \\
\text { (ajustável dos dois } \\
\text { lados) }\end{array}$ & $x$ & $\begin{array}{c}\text { Pincel Troca } \\
\text { Cerdas }\end{array}$ \\
\hline Pincel Troca Cerdas & Pincel Troca Cerdas & Pincel Troca Cerdas & $\mathrm{X}$ \\
\hline $\begin{array}{l}\text { Coletor de pilhas e } \\
\text { eletrônicos }\end{array}$ & $\begin{array}{l}\text { Coletor de pilhas e } \\
\text { eletrônicos }\end{array}$ & $\begin{array}{l}\text { Coletor de pilhas e } \\
\text { eletrônicos }\end{array}$ & $\begin{array}{l}\text { Coletor de pilhas e } \\
\text { eletrônicos }\end{array}$ \\
\hline
\end{tabular}

$\mathrm{Na}$ etapa seguinte (desenvolvimento e teste de conceito) foi realizado um questionário submetido a três parcelas da população: professores da Educação Infantil, alunos de curso profissionalizante e amadores do artesanato. Dessa forma, foi possível elaborar gráficos com os dados obtidos e comparar as respostas.

A primeira pergunta do questionário foi "Você consome produtos desse estilo? (Pincel de artesanato)". O Gráfico 2 apresenta as informações referentes às respostas dessa questão. Com esses dados, concluiu-se que os professores da Educação Infantil são a parcela de entrevistados que consome pincéis de artesanato com maior frequência, com 17,95\%, seguido dos alunos do curso profissionalizante, com $15,38 \%$ e amadores do artesanato, com $10,26 \%$. 
Eloiza Kohlbeck, Beatriz Christina Baimler, Fernanda Hansch Beuren, Alexandre Borges Fagundes, Delcio Pereira

Gráfico 2 - Consumo de pincéis de artesanato.

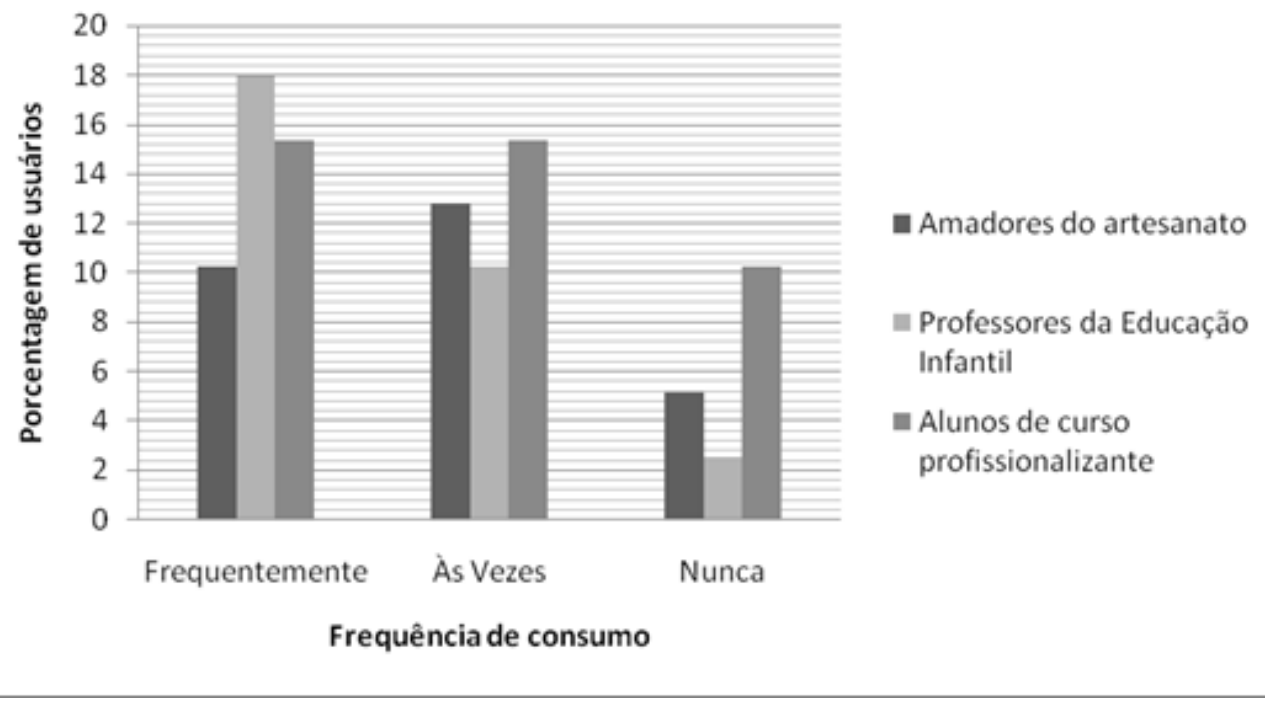

Fonte: elaborado pelos autores (2019).

O Gráfico 3 apresenta os dados obtidos com base na segunda pergunta, "Qual sua periodicidade de compra por pincéis de artesanato?". Com esta questão foi possível constatar que os professores da Educação Infantil foram a parcela de analisados que adquire pincéis de artesanato com maior periodicidade, dos quais $15,38 \%$ responderam que adquirem pincéis pelo menos uma vez por mês, e que nenhum professor afirmou nunca ter comprado esse produto.

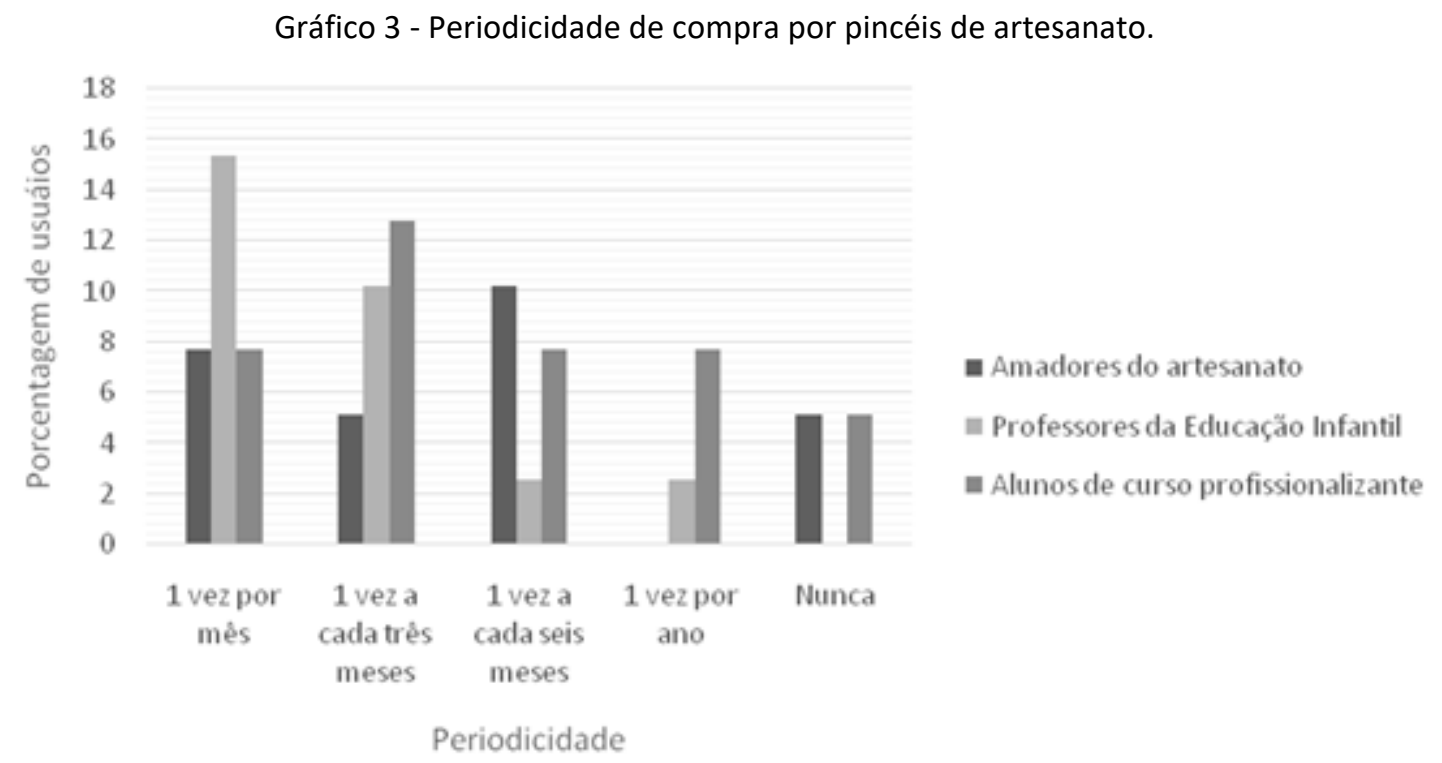

Fonte: elaborado pelos autores (2019). 
A terceira pergunta, "Quantos itens você adquire, em média, em cada compra?" apresentou como resultados os dados contidos no Gráfico 4. Com esta análise conclui-se que os alunos do curso profissionalizante representam uma parcela que adquire menos itens por compra, com o percentual de $23,08 \%$. Os professores da Educação Infantil que adquirem de quatro ou mais pincéis a cada compra representam $12,82 \%$ da parcela total de entrevistados.

Gráfico 4 - Quantidade média de produtos adquiridos em cada compra.

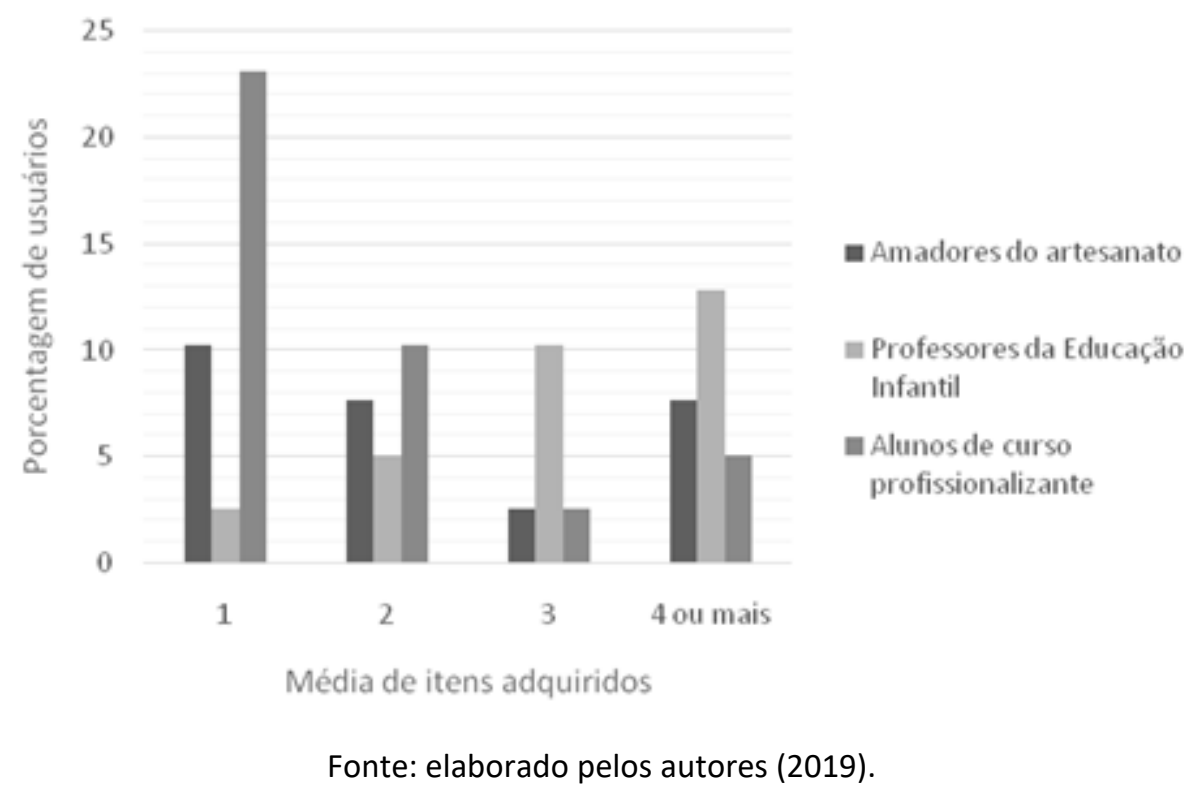

A quarta pergunta descreve qual seria a atitude do entrevistado em relação à compra do produto "Pincel Troca Cerdas". Seu resultado pode ser observado no

Gráfico 5. A partir deste gráfico, observou-se que os professores da Educação Infantil foram a parcela de entrevistados que apresentou a melhorar aceitabilidade em relação a compra, com 23,08\% que afirmaram certamente comprar o "Pincel Troca Cerdas". Também foi possível concluir que não houve respostas desfavoráveis a compra do produto.

Na pergunta seguinte foi questionado sobre a aceitabilidade dos entrevistados pelo "Pincel Troca Cerdas", com a utilização de uma escala de 0 a 10. Com isso, foi calculada uma média de cada uma das três parcelas da população analisada, conforme Gráfico 6. 
Eloiza Kohlbeck, Beatriz Christina Baimler, Fernanda Hansch Beuren, Alexandre Borges Fagundes, Delcio Pereira

Gráfico 5 - Atitude do entrevistado em relação à compra.

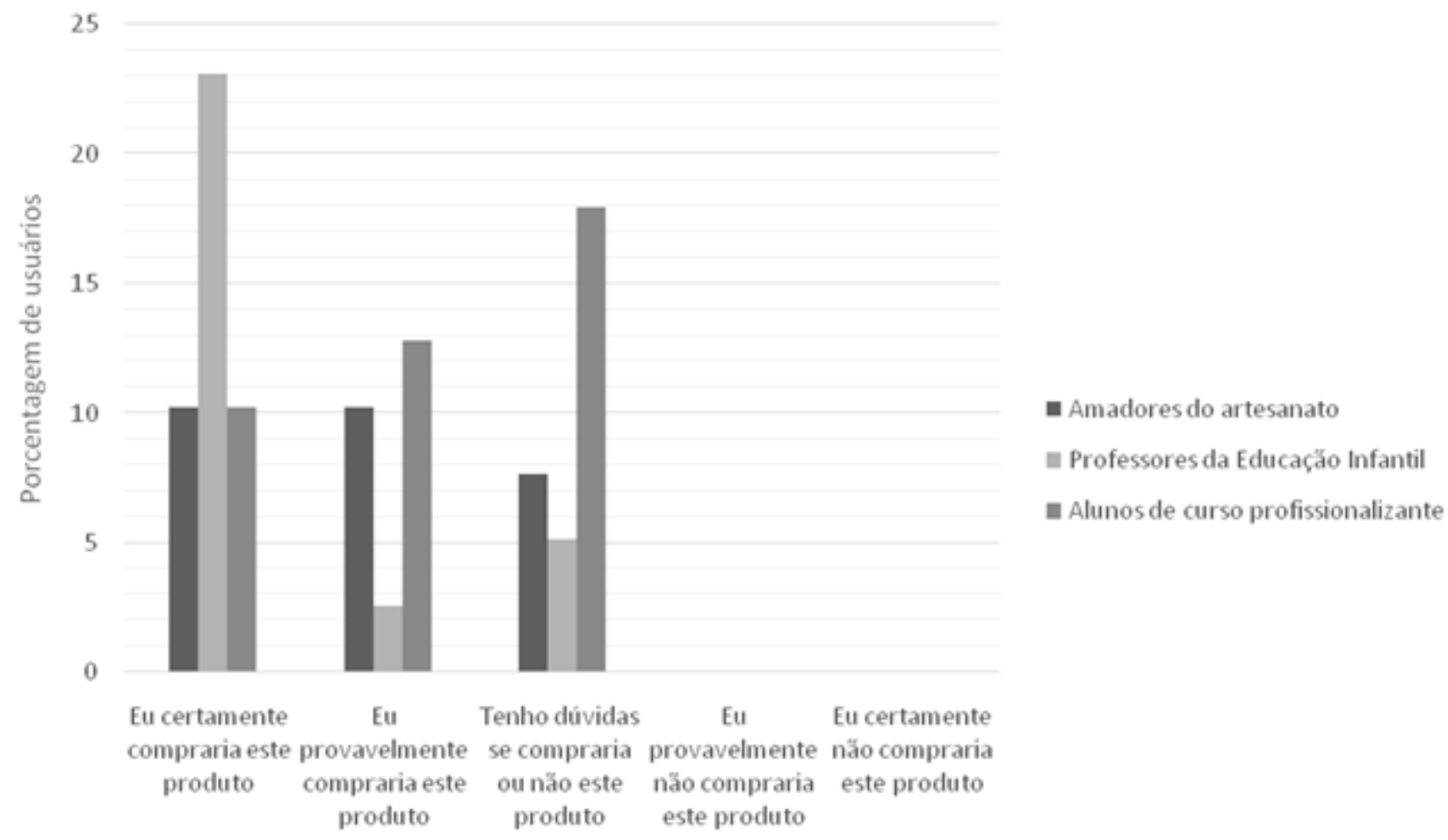

Atitude em relação a compra

Fonte: elaborado pelos autores (2019).

Gráfico 6 - Média de aceitabilidade dos entrevistados.

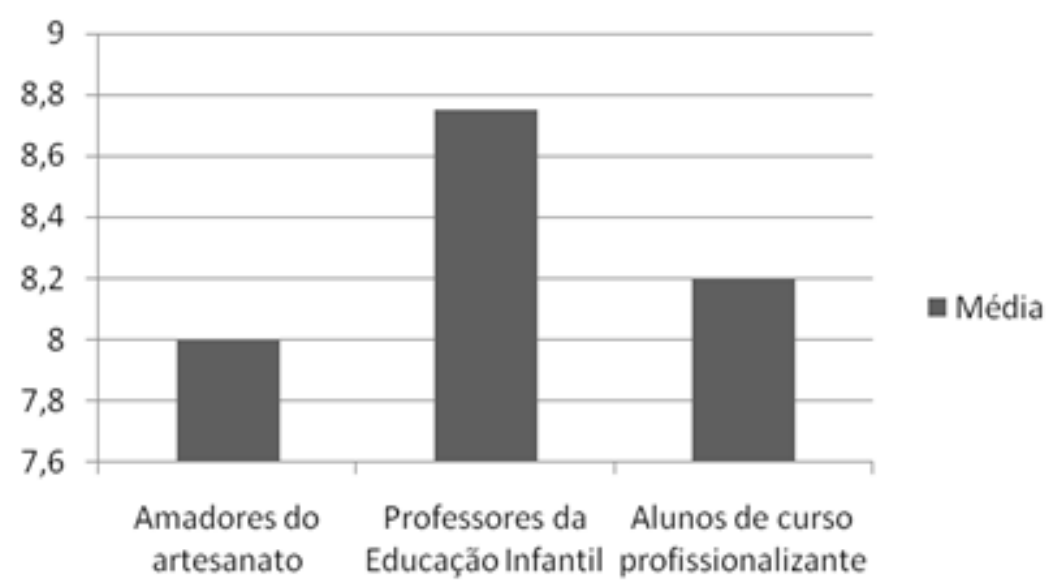

Fonte: elaborado pelos autores (2019).

Ao considerar que os professores da Educação Infantil apresentaram boa aceitabilidade, que adquirem grande quantidade de produtos em cada compra e os adquirem com frequência, foram a parcela que melhor avaliou o "Pincel Troca Cerdas", sendo sua média de modo isolado em 8,75. Em 
seguida, a média dos alunos do curso profissionalizante ficou em 8,2 e dos amadores do artesanato em 8,0. A média geral de todos os analisados ficou 8,3.

Na sequência, perguntou-se qual ou quais dos aspectos listados atraem a atenção do consumidor em relação ao produto. Também foi oferecida a opção "outro", na qual o entrevistado, ao assinalá-la, deveria descrever o aspecto. Nessa opção foram citados aspectos como a praticidade, portabilidade, sustentabilidade e versatilidade. Essas informações podem ser observadas no Gráfico 7, no qual observa-se que dentre os fatores listados, a simplicidade e a facilidade de uso foram os aspectos que mais chamaram a atenção do consumidor e que possivelmente seriam fatores determinantes na compra do produto.

Gráfico 7 - Aspectos atrativos do "Pincel Troca Cerdas".

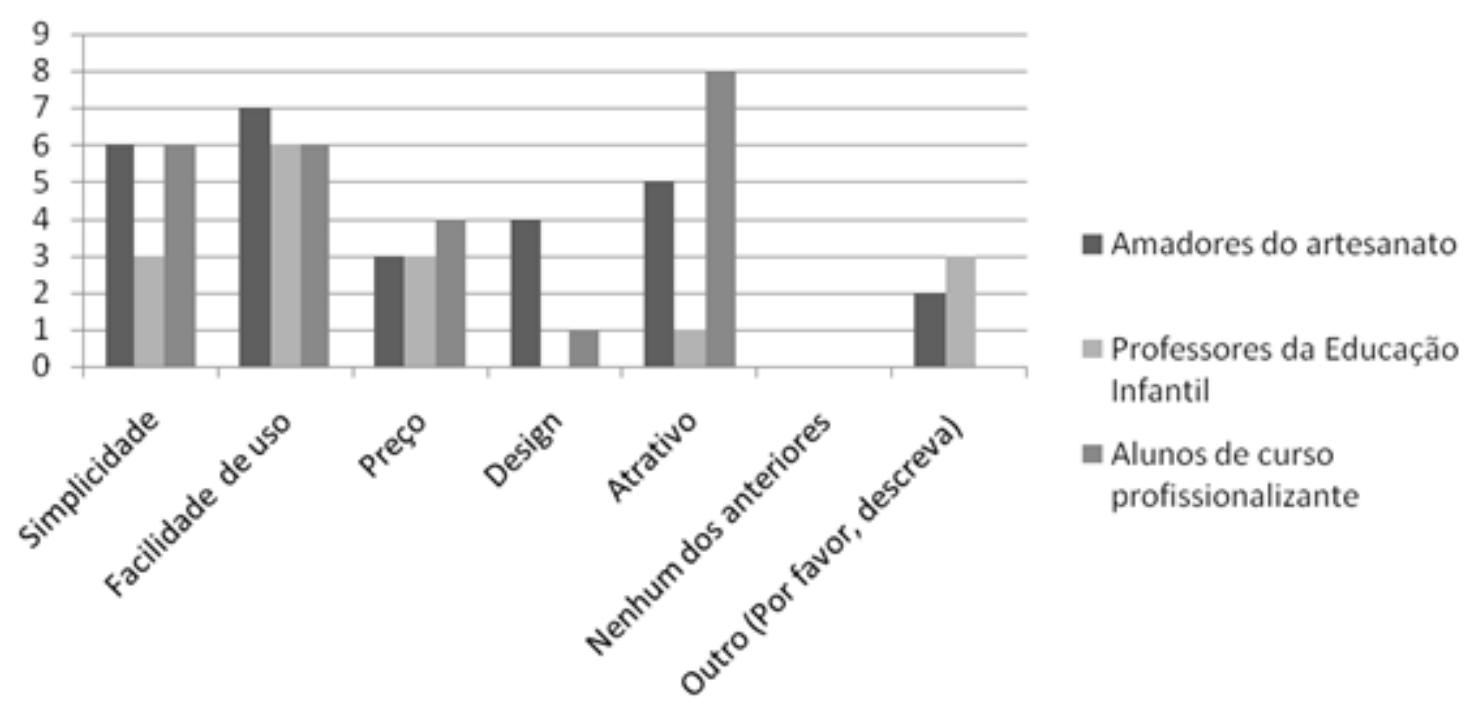

Fonte: elaborado pelos autores (2019).

O Gráfico 8 apresenta os dados fornecidos pela última pergunta "Você tem algum comentário ou sugestão sobre este produto?". Entre os entrevistados que assinalaram a opção "Sim", duas pessoas disseram não ser possível avaliar o produto sem que todas suas etapas de fabricação fossem concluídas. Os entrevistados que assinalaram a opção "Sim" parabenizaram a iniciativa e mostraram-se favoráveis a fabricação do produto.

Após obtidos estes dados, percebeu-se que o produto apresentou uma boa aceitabilidade por parte dos entrevistados. Dessa forma, concluiu-se que sua fabricação é uma medida viável. A 
partir do questionário foi possível fazer um estudo do mercado no qual o produto "Pincel Troca Cerdas" será lançado, visto que nas perguntas elaboradas foram analisadas questões comportamentais dos entrevistados.

Gráfico 8 - Comentários e sugestões.

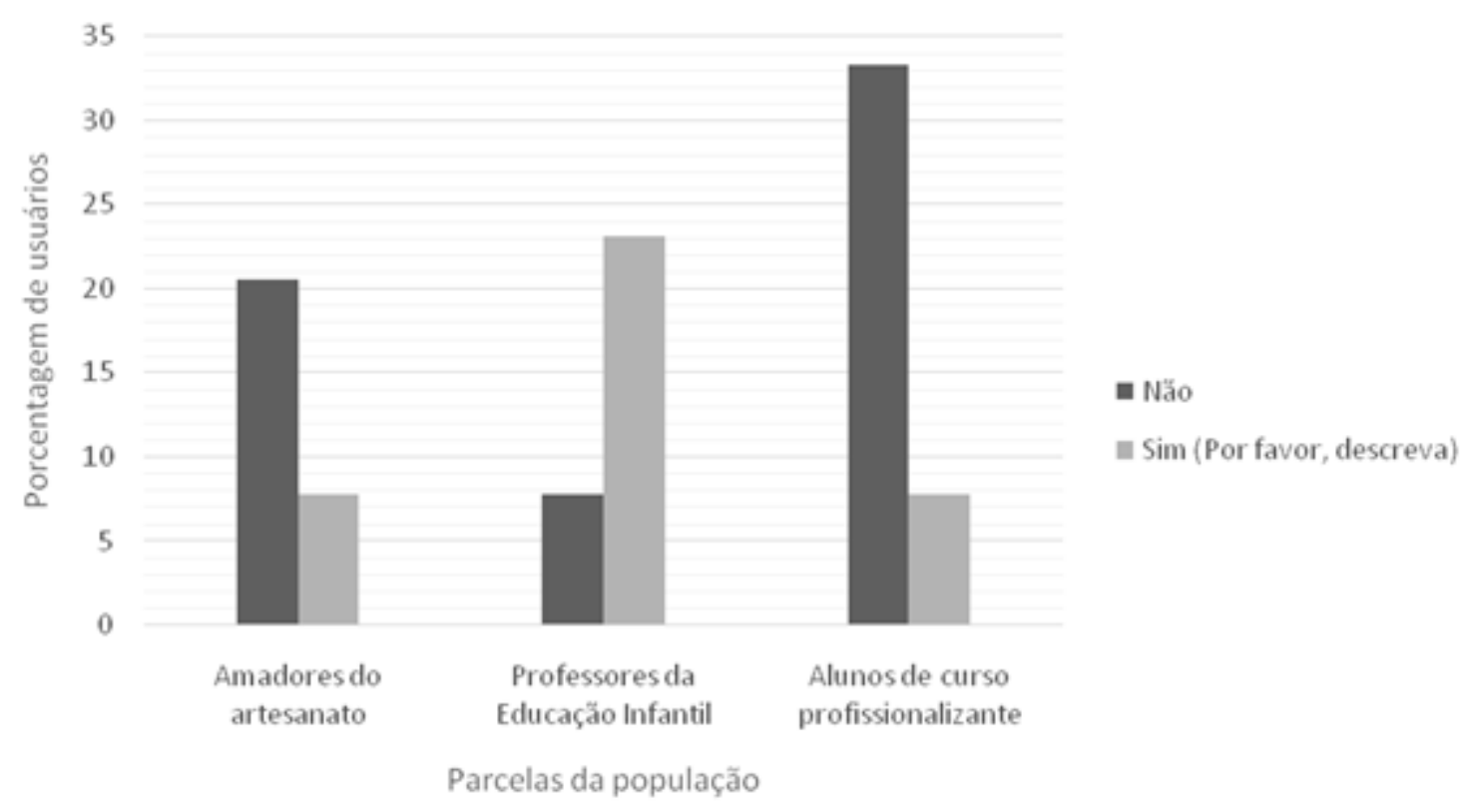

Fonte: elaborado pelos autores (2019).

Conclui-se que dentre as três parcelas da população analisada, os professores da Educação Infantil apresentaram uma melhor aceitabilidade pelo produto em questão, além de consumirem pincéis de artesanato com frequência e em grande quantidade. Dessa forma, os profissionais desta área tornaram-se o público alvo do produto. Entretanto, a divulgação e comercialização do "Pincel Troca Cerdas" também se dará nas outras áreas, visto que o resultado do questionário foi positivo para todas as parcelas analisadas e que a diferença entre os dados obtidos foi pequena. Dessa forma, a abrangência do mercado é grande.

Na etapa seguinte, foi estipulado o valor de comercialização do "Pincel Troca Cerdas". Para isso, foram comparados os preços em diversas lojas, objetivando encontrar aquele com o melhor preço e com boa qualidade. Assim, foram listados todos os custos gerados com a compra de materiais. A primeira análise foi feita com os preços (média) dos pincéis e do rolo de artesanato, conforme Tabela 1. 
Eloiza Kohlbeck, Beatriz Christina Baimler, Fernanda Hansch Beuren, Alexandre Borges Fagundes, Delcio Pereira

Tabela 1 - Análise de custos de pincéis de artesanato.

\begin{tabular}{cccc}
\hline $\begin{array}{c}\text { Tamanho do } \\
\text { pincel }\end{array}$ & Preço & $\begin{array}{c}\text { Tamanho } \\
\text { do pincel }\end{array}$ & Preço \\
\hline $\mathbf{2}$ & $\mathrm{R} \$ 1,99$ & 12 & $\mathrm{R} \$ 3,29$ \\
$\mathbf{4}$ & $\mathrm{R} \$ 2,29$ & 14 & $\mathrm{R} \$ 3,79$ \\
$\mathbf{6}$ & $\mathrm{R} \$ 2,39$ & 16 & $\mathrm{R} \$ 4,39$ \\
$\mathbf{8}$ & $\mathrm{R} \$ 2,59$ & 18 & $\mathrm{R} \$ 4,79$ \\
$\mathbf{1 0}$ & $\mathrm{R} \$ 2,89$ & 20 & $\mathrm{R} \$ 6,29$ \\
$\begin{array}{c}\text { Rolo de } \\
\text { artesanato }\end{array}$ & $\mathrm{R} \$ 1,89$ & & \\
& & TOTAL & $\mathrm{R} \$ 36,59$ \\
\hline \multicolumn{2}{c}{ Fonte: elaborada pelos autores (2019). }
\end{tabular}

A seguir, foram comparados os preços para a confecção do cabo do pincel, constituído por um tubo com roscas em suas extremidades. O preço mais barato e de melhor qualidade foi encontrado por $\mathrm{R} \$ 10,83$. As roscas, presentes na base de cada pincel e do rolo, que encaixam no cabo, foram analisados e o preço mais acessível foi encontrado por $\mathrm{R} \$ 1,56$ a unidade, totalizando $\mathrm{R} \$$ 17,16 , pois são 10 roscas para os pincéis e uma rosca para o rolo.

Por fim, foi estipulado o menor preço para a confeç̧ão da embalagem, composta pela caixa e por uma espuma para apoio dos pincéis, do rolo e do cabo, resultando em um valor de $\mathrm{R} \$ 14,90$.

No total, o preço de fabricação do "Pincel Troca Cerdas" resultou em R\$ 79,48. Dessa forma, foi possível estipular o valor de comercialização do produto, que resultou em $R \$ 110,00$, oferecendo uma margem de lucro de 40\%. Esses dados podem ser observados na Tabela 2.

Tabela 2 - Estimativa de valores para meta de 30 produtos ao mês.

\begin{tabular}{|c|c|c|c|}
\hline & Valor para confecção & Valor de comercialização & Valor líquido/ lucro \\
\hline $\begin{array}{c}\text { Valor } \\
\text { unitário }\end{array}$ & $R \$ 79,48$ & $\mathrm{R} \$ 110,00$ & $R \$ 30,52$ \\
\hline $\begin{array}{c}30 \\
\text { unidades }\end{array}$ & $\mathrm{R} \$ 2.384,40$ & $\mathrm{R} \$ 3.300,00$ & $\mathrm{R} \$ 915,60$ \\
\hline
\end{tabular}

Também haverá a opção de compra do produto sem a embalagem, reduzindo o valor de comercialização e dos impactos ambientais. Dessa forma, o preço de fabricação é reduzido à R\$64,58. 
Ao adicionar a margem de lucro de $40 \%$, o valor de comercialização será de $\mathrm{R} \$ 90,00$. Esses valores estão apresentados na Tabela 3.

Tabela 3 - Opção de venda do kit sem a embalagem.

\begin{tabular}{cccc}
\hline & Valor para confeç̧ão & Valor de comercialização & Valor líquido/ lucro \\
\hline $\begin{array}{c}\text { Valor } \\
\text { unitário }\end{array}$ & $\mathrm{R} \$ 64,58$ & $\mathrm{R} \$ 90,00$ & $\mathrm{R} \$ 25,42$ \\
$\mathbf{3 0}$ & $\mathrm{R} \$ 1.937,40$ & $\mathrm{R} \$ 2.700,00$ & $\mathrm{R} \$ 762,60$ \\
\hline unidades & . & & \\
\hline
\end{tabular}

Fonte: elaborada pelos autores (2019).

Em seguida, foi estipulada a estratégia de distribuição, onde a proposta de venda ocorrerá em uma plataforma on-line (marketplace) e em classificados regionais. Visto que os professores da Educação Infantil apresentaram uma boa aceitabilidade pelo produto, tornam-se o público alvo para comercialização.

A divulgação ocorrerá por meio de postagens online em redes sociais das instituições de ensino e por comercialização direta entre consumidores. Entretanto, as outras parcelas da população também estarão inseridas nos planos de distribuição, de modo a manter uma constante procura por novos ambientes de venda.

Com o meta de venda, foi estipulado um comércio mínimo para o primeiro mês: cinco produtos para os professores da Educação Infantil, quatro para a população em geral e três para os alunos do curso profissionalizante, de modo a gerar um lucro bruto de $\mathrm{R} \$ 1.320,00$ e um lucro líquido de $R \$ 366,24$.

Também haverá a procura em firmar parceria com entidades que promovam curso de trabalhos artesanais, oferecendo o kit para o uso durante as atividades e para posterior aquisição por parte dos interessados, de modo a garantir o conhecimento do produto e a constante divulgação por meio de turmas subsequentes. Se houver a comercialização média de 30 produtos ao mês, o lucro líquido anual será de $\mathrm{R} \$ 10.987,20$.

Além de listar os custos fixos, também há a necessidade de considerar os custos variáveis, representados na Quadro 3. 
Eloiza Kohlbeck, Beatriz Christina Baimler, Fernanda Hansch Beuren, Alexandre Borges Fagundes, Delcio Pereira

Quadro 3 - Análises de custo.

\begin{tabular}{|l|l|}
\hline Custo fixo & Custo variado \\
\hline \multirow{3}{*}{ Insumos } & Despesa com marketing \\
\cline { 2 - 2 } & Doação de kits para cursos de artesanato \\
\cline { 2 - 2 } & Deslocamento para divulgação/distribuição \\
\hline
\end{tabular}

Decorrido o primeiro mês de comercialização do "Pincel Troca Cerdas", será possível realizar uma análise do cumprimento da meta estipulada e uma avaliação da aceitabilidade. Dessa forma, pode-se verificar qual grupo adquiriu maior quantidade do produto, para que seja possível fortalecer a propaganda para essa parcela da população e rever a estratégia de venda dos outros grupos. Para os meses seguintes, a meta será dobrar o número de unidades vendidas no primeiro mês, de modo a manter constante ou aumentar essa quantidade.

Em relação ao marketing, o orçamento deve ser o menor possível, tendo em vista a divulgação do produto de forma gratuita através de sites e outras redes sociais, além da divulgação entre profissionais, onde não há gastos significativos com marketing.

A etapa seguinte foi a confecção do desenho técnico do "Pincel Troca Cerdas", para o qual foi utilizado o software Autodesk Inventor. A Figura 3 apresenta a montagem final do produto.

Figura 3 - Desenho técnico do Pincel Troca Cerdas.

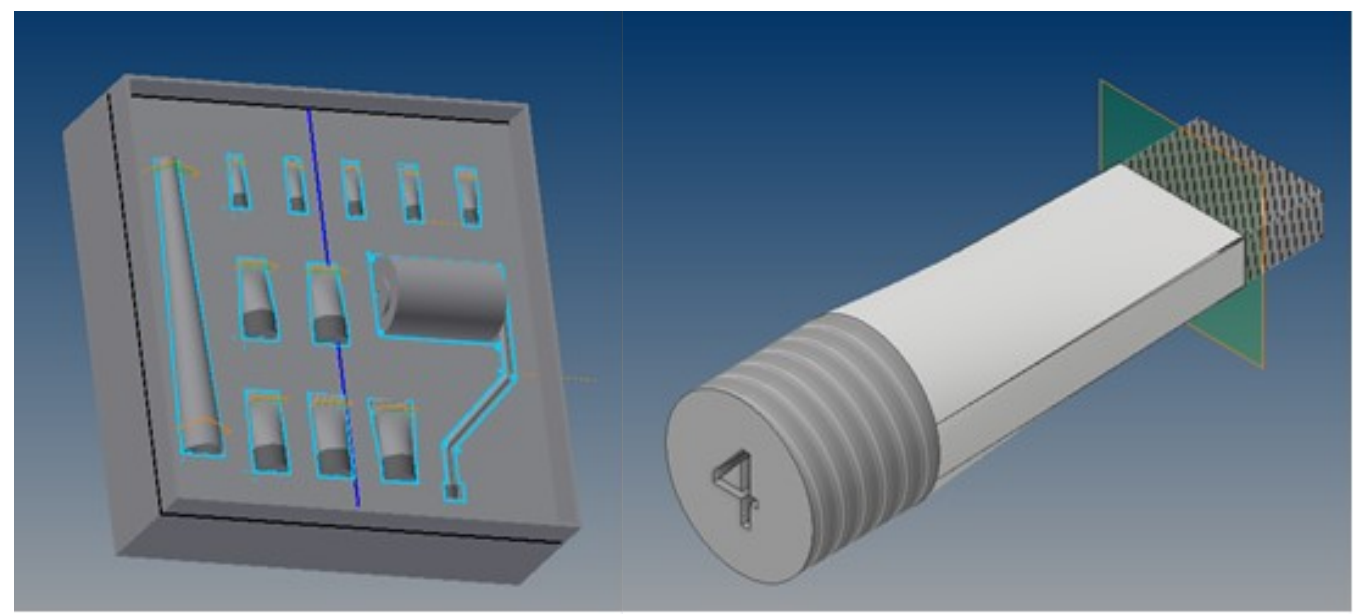

Fonte: elaborada pelos autores (2019). 
Eloiza Kohlbeck, Beatriz Christina Baimler, Fernanda Hansch Beuren, Alexandre Borges Fagundes, Delcio Pereira

Por meio do desenho computacional, foi realizada a prototipagem do produto com impressão 3D, que possibilitou a visualização do "Pincel Troca Cerdas" com alto nível de detalhamento. A Figura 4 demonstra este processo.

Figura 4 - Impressão 3D do protótipo.

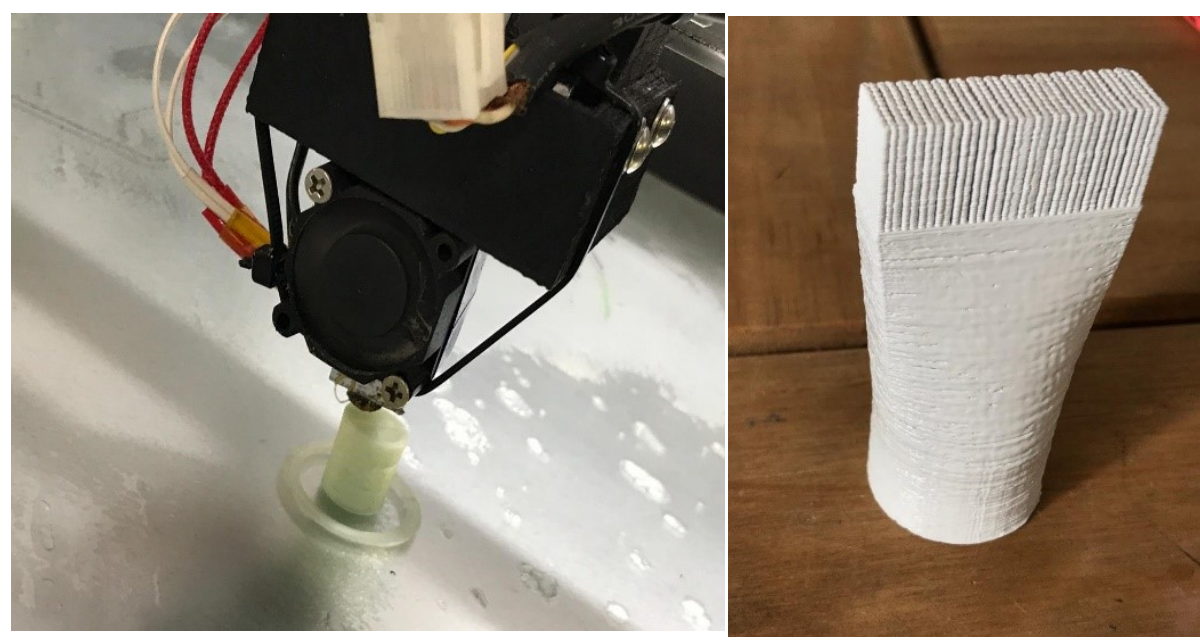

Fonte: elaborada pelos autores (2019).

Também foi realizada a prototipagem em escala real com a utilização de material alternativo, conforme ilustra a Figura 5.

Figura 5 - Prototipagem.

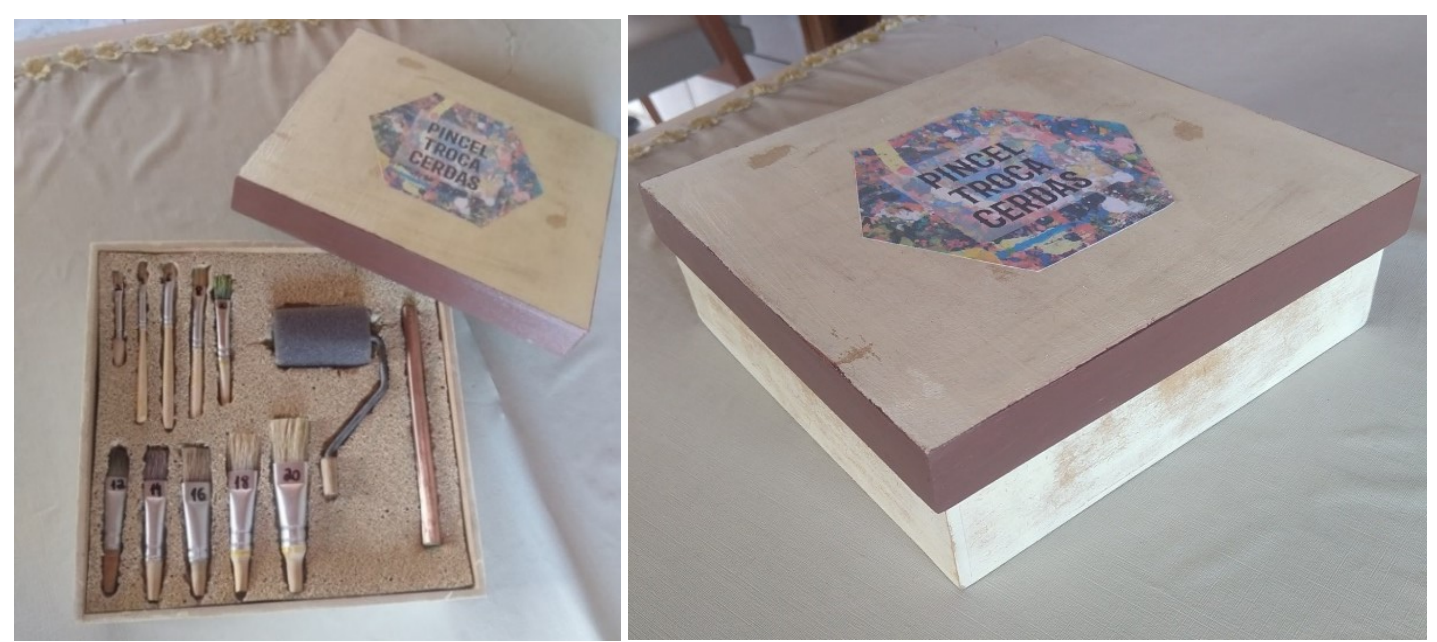

Fonte: elaborada pelos autores (2019). 

Delcio Pereira

O produto desenvolvido irá permitir que o consumidor utilize 10 tamanhos diferentes de pincéis e/ou um rolo de artesanato, usando somente um cabo para encaixar (através de uma rosca) os pincéis e/ou o rolo. Assim, o consumo de matéria-prima e de embalagens é reduzido.

Os tamanhos de pincéis são contados de dois em dois, sendo que o "Pincel Troca Cerdas" é composto por pincéis do tamanho dois ao 20, totalizando as 10 opções disponíveis. Do pincel de número dois ao 10, incluindo também o rolo, o encaixe é feito na parte superior do cabo. Já do pincel 12 ao 20 , o encaixe é feito na parte inferior do mesmo.

Assim, a comercialização do produto pode ser iniciada e, para as vendas serem satisfatórias, será realizada pesquisa de satisfação na plataforma on-line e com as pessoas em geral, de modo a montar gráficos comparativos dos meses anteriores.

\section{CONCLUSÃO}

Este trabalho teve como objetivo a proposta de desenvolvimento de um novo produto que amenize os impactos da poluição do solo, sendo que há uma elevada geração de resíduos devido ao descarte de produtos. Processos como a obsolescência programada, a busca constante do consumidor pela renovação de produtos e o aumento populacional intensificam a geração de resíduos. Visto que o descarte contribui para este contexto, o produto confeccionado foi o "Pincel Troca Cerdas", que em sua utilização, o consumidor dispõe somente de um cabo, que o permite usar 10 tamanhos diferentes de pincéis de artesanato e/ou um rolo, dispostos em uma única embalagem.

A pesquisa concluiu que o "Pincel Troca Cerdas" satisfez a proposta metodológica de atenuar os impactos ambientais, gerando menor quantidade de resíduos, pois minimiza o consumo de embalagens e de material para confecção. Também foi possível concluir que a praticidade é um fator essencial no momento de desenvolver produtos, visto que a demanda por esse tipo de mercadoria cresce exponencialmente. Entretanto, a praticidade deve estar diretamente interligada com a sustentabilidade, pois o consumo prático não pode levar à aquisição excessiva de produtos, que geram quantidades significativas de embalagens e que serão futuramente descartadas, tornando-se fonte de poluição.

Ainda, pode-se compreender a importância das etapas do pré-desenvolvimento, pois seu caráter estratégico facilita e otimiza processos futuros, como a fabricação e a comercialização. Dessa 
forma, a metodologia empregada mostrou-se apropriada como experiência didática e eficiente para o desenvolvimento de novos produtos.

Produtos e serviços podem amenizar os impactos ambientais, porém é necessária uma conscientização coletiva, que resulte em ações que contribuam para melhorar a qualidade de vida da população, com a introdução de novos hábitos e costumes na sociedade.

Sabendo que a poluição do solo é um tema muito abrangente, existem inúmeras oportunidades e possibilidades de criação e utilização de novos produtos. Dessa forma, não se pode dar por encerrada esta pesquisa, pois muitas áreas do conhecimento podem ser exploradas para amenizar este problema.

\section{REFERÊNCIAS}

ABRE. Produção física de embalagens cresce 2,5\% em 2018 e apresenta perspectivas positivas para os próximos anos. 15 mar. 2019. Disponível em: http://www.abre.org.br/noticias/producaofisica-de-embalagens-cresce-25-em-2018-e-apresenta-perspectivas-positivas-para-os-proximosanos/. Acesso em: 21 set. 2019.

BARRADAS, Sarah; MARTINS, Márcio; Rinaldo MORAES. A importância da prática da logística reversa como ferramenta de responsabilidade socioambiental no setor de bebidas. In: SIMPÓSIO DE EXCELÊNCIA EM GESTÃO E TECNOLOGIA, 8., 2011, Resende. Anais [...]. [S.I.]: Associação Educacional Dom Bosco, 2011. p. 01-13. Disponível em: https://www.aedb.br/seget/arquivos/artigos11/25614217.pdf. Acesso em: 02 abr. 2019.

BRASIL. Ministério do Meio Ambiente. Impacto das embalagens no meio ambiente. Disponível em: http://www.mma.gov.br/responsabilidade-socioambiental/producao-e-consumosustentavel/consumo-consciente-de-embalagem/impacto-das-embalagens-no-meio-ambiente. Acesso em: 28 set. 2018.

BULLARD, Olya; MANCHANDA, Rajesh V. Do sustainable products make us prevention focused? Mark Lett, v. 24, p. 177-189, 2013. Disponível em: https://link-springercom.ez74.periodicos.capes.gov.br/content/pdf/10.1007\%2Fs11002-012-9221-2.pdf. Acesso em: 25 set. 2019.

BURGHARDT, J. E. et al. Conceitos aplicados à poluição do solo decorrente do derrame de petróleo e seus derivados. Revista Maiêutica, Indaial, v. 4, n. 1, p. 7-14, 2016. Disponível em: https://publicacao.uniasselvi.com.br/index.php/GAM_EaD/article/view/1533/669. Acesso em: 06 dez. 2018.

CALMANOVICl, C. E. A inovação, a competitividade e a projeção mundial das empresas brasileiras. Revista USP, São Paulo, n. 89, maio 2011. Disponível em: 
http://rusp.scielo.br/scielo.php?script=sci_arttext\&pid=S0103-

99892011000200013\&lng=pt\&nrm=iso. Acesso em: 18 jan. 2019.

CAMPOS, F.; GAIÃO, I. F. Análise comparativa da experiência das técnicas criativas Brainstorming e Método 635 a partir da Teoria da Atividade. Ergotrip Design, n. 1, p. 10-19, 2015. Disponível em: http://revistas.ua.pt/index.php/ergotripdesign/article/view/4103/3978. Acesso em: 14 jan. 2019.

COSTA, M. A. B.; TOLEDO, J. C. Análise dos modelos e atividades do pré-desenvolvimento: revisão bibliográfica sistemática. Gestão \& Produção, São Carlos, v. 23, n. 4, p. 704-717, dez. 2016. Disponível em: http://www.scielo.br/scielo.php?script=sci_arttext\&pid=S0104530X2016000400704 \&lng=pt\&nrm=isso. Acesso em: 15 nov. 2018.

CROCKER, Robert. Somebody else's problem: consumerism, sustainability \& design. New York: Taylor \& Francis Group, 2017. Disponível em: https://www.crcpress.com/Somebody-Elses-ProblemConsumerism-Sustainability-and-Design/Crocker/p/book/9781783534913. Acesso em: 24 set. 2019.

CUNHA, Julio Araujo Carneiro da et al. Desempenho de serviços e produtos em uma rede de franquias de fast food: reflexões acerca do modelo de entrega em domicílio. In: CONGRESSO LATINO-AMERICANO DE VAREJO E CONSUMO, 12., 2017, São Paulo. Anais [...]. São Paulo: FGV, 2017. p. 01-11. Disponível em:

http://bibliotecadigital.fgv.br/ocs/index.php/clav/clav2017/paper/view/6019. Acesso em: 22 set. 2019.

DIAS, Juliana de Carvalho. Rotas de destinação dos resíduos plásticos e seus aspectos ambientais: uma análise da potencialidade da biodegradação. 2016. 72f. Dissertação (Mestrado em Planejamento Energético) - Instituto Alberto Luiz Coimbra de Pós-Graduação e Pesquisa de Engenharia, Universidade Federal do Rio de Janeiro, Rio de Janeiro, 2016. Disponível em: http://www.ppe.ufrj.br/images/publica\%C3\%A7\%C3\%B5es/mestrado/Juliana_de_Carvalho_Dias.p df. Acesso em: 21 set. 2019.

FAGUNDES, Alexandre Borges. Modelagem fuzzy para avaliação de desempenho ambiental do gerenciamento de resíduos sólidos industriais. 2015. $213 \mathrm{f}$. Tese (Doutorado em Tecnologia) Universidade Tecnológica Federal do Paraná, Curitiba, 2015 Disponível em:

http://repositorio.utfpr.edu.br/jspui/handle/1/1140. Acesso em: 12 out. 2018.

FERREIRA, M. G. G.; MICHELS, E. Gerenciamento ágil no processo de desenvolvimento de produtos inovadores: Uma análise bibliográfica sistemática. Revista de Gestão e Projetos, São Paulo, v. 4, n. 1, p. 52-76, jan./abr.2013.Disponível em: https://dialnet.unirioja.es/descarga/articulo/5078069.pdf. Acesso em: 07 dez 2018.

FREITAS, Ana Luiza Cerqueira; ROMEIRO, Eduardo Filho. Desenvolvimento de produtos para a produção artesanal. In: ENCONTRO NACIONAL DE ENGENHARIA DE PRODUÇÃO, 24., 2004, Florianópolis. Anais [...]. Florianópolis: ABEPRO, 2004. p. 349-356. Disponível em: 
http://www.abepro.org.br/biblioteca/enegep2004_enegep0103_0807.pdf. Acesso em: 28 mar. 2019.

MAFRA, José Roberto Dourado; VIDAL, Mario Cesar Rodríguez. Inovação e ergonomia: novos produtos, novos processos ou novos paradigmas. Sociedade, contabilidade e gestão, Rio de Janeiro, v. 3, n. 2, jul./dez. 2008. Disponível em: http://atena.org.br/revista/ojs-2.2.306/index.php/ufrj/article/view/462/450. Acesso em: 30 mar. 2019.

MANZINI, Ezio; VEZZOLI, Carlo. O desenvolvimento de produtos sustentáveis: os requisitos ambientais dos produtos industriais. São Paulo: Editora da Universidade de São Paulo, 2016.

MAXWELL, Dorothy; SHEATE, William; VORST, Ritavan der. Functional and systems aspects of the sustainable product and service development approach for industry. Journal of Cleaner Production, v. 14, n. 17, p. 1466-1479, 2006. Disponível em: https://www-

sciencedirect.ez74.periodicos.capes.gov.br/science/article/pii/S0959652606000783. Acesso em: 22 set. 2019.

ROZENFELD, H.; FORCELLINI, F.A.; AMARAL, D.C.; TOLEDO, J.C.; SILVA, S.L.; ALLIPRANDINI, D.H.; SCALICE, R.K. Gestão de desenvolvimento de produtos: uma referência para a melhoria do processo. São Paulo: Saraiva, 2006.

SILVEIRA, Roberto Patrocinio. Conhecimento em resíduos sólidos e coleta seletiva na era da reutilização e da reciclagem: o ex-lixo como pilar de uma sociedade mais inclusiva e menos insustentável. Brasília, 2014. 133 p. Monografia (Graduação) - Universidade de Brasília, Departamento de Geografia. Disponível em: http://bdm.unb.br/bitstream/10483/9855/1/2014_ RobertoPatrocinioSilveira.pdf. Acesso em: 07 abr. 2019.

SLOMSKI, Valmor et al. Sustentabilidade nas organizações: a internalização dos gastos com o descarte do produto e/ou embalagem aos custos de produção. Revista de Administração, São Paulo, v. 47, n. 2, p. 275-289, jul. 2012. Disponível em:

http://www.scielo.br/scielo.php?script=sci_arttext\&pid=S0080-

$21072012000200009 \&$ Ing=en\&nrm=iso. Acesso em: 21 set. 2019.

SOUZA, Adriano José Sorbile de. Design como forma de inovação no Processo de Desenvolvimento de Produtos (PDP) e seus conceitos metodológicos. Di Factum, Lorena, v. 1, n. 1, p. 69-74, set./dez., 2016. Disponível em: http://fatea.br/seer3/index.php/Difactum/article/view/23/19. Acesso em: 22 set. 2019.

STOCK, T.; SELIGER, G. Opportunities of sustainable manufacturing in industry 4.0. Elsevier B.V. 2016. Disponível em: https://www.sciencedirect.com/science/article/pii/S221282711600144X. Acesso em: 21 set. 2019.

TROTT, P. Gestão da inovação e desenvolvimento de novos produtos. 4. ed. Porto Alegre: Bookman, 2012. 
VENTURA, Rodrigo. Mudanças no perfil do consumo no Brasil: principais tendências nos próximos 20 anos. Macroplan, [s.I.], p. 01-15, 2010. Disponível em:

http://macroplanconsultoria.com.br/Documentos/ArtigoMacroplan2010817182941.pdf. Acesso em: 30 mar. 2019.

VIANNA, Anderson Martins. Poluição ambiental, um problema de urbanização e crescimento desordenado das cidades. Revista SUSTINERE, Rio de Janeiro, v. 3, n. 1, p. 22-42, jan./jun., 2015. Disponível em: http://www.e-publicacoes.uerj.br/index.php/sustinere/article/view/17325/12855. Acesso em: 09 out. 2018. 